\title{
LOS "CUADERNOS DE CAMPO" Y ESBOZOS HISTOLÓGICOS EN LA OBRA DE SALVADOR GIL VERNET.
}

\author{
Antoni Gelabert Mas.
}

Servicio y Cátedra de Urología. Hospital del Mar. Universidad Autónoma de Barcelona. Barcelona. España.

\begin{abstract}
Resumen.- Trabajo basado en 11 libretas de campo, con sus anotaciones y descripciones de las preparaciones anatómicas macro y microscópicas. Existe además un cuaderno con varios dibujos hechos a mano y a lápiz de mina negra, que reproducen la anatomía microscópica del cuello; además cinco láminas de formato $60 \times 40 \mathrm{~cm}$. de dibujos histológicos, varias preparaciones histológicas, así como algunos papeles de carta con el membrete de Don Salvador en sus distintas facetas institucionales.
\end{abstract}

Palabras clave: Cuadernos de campo. Cáncer de próstata. Salvador Gil Vernet. Historia de la Urología.
Summary.- Our work is based on 11 field notebooks with his notes and descriptions of macroscopic and microscopic anatomic preparations. There is also one notebook with several handmade drawings on black lead pencil, reproducing the microscopic anatomy of the bladder neck; there are also five $60 \times 40 \mathrm{~cm}$ prints with histologic drawings, several histologic preparations, as well as several letter papers with Dr. Salvador's letterhead in his various institutional aspects.

Keywords: Field notebooks. Prostate cancer. Salvador Gil Vernet. History of Urology.

\section{INTRODUCCIÓN}

Siempre resulta difícil hablar de alguien a quien o bien no has conocido personalmente, o sólo tienes referencias a través de terceros o bien sólo tienes un conocimiento intelectual a través de su obra.

En mi caso, hablar del Prof. Salvador Gil Vernet, Don Salvador o Dr. Gil, como familiarmente le llamábamos los que estábamos en el círculo profesional próximo, me supone partir de una dualidad poco frecuente.

En primer lugar tuve el privilegio de conocerlo personalmente, de pasar largos ratos con él en su viejo despacho de la Cátedra de Urología del Hospital Clínic i Provincial, el Clinic, de acompañarlo en algunas visitas a otras salas del Hospital para hablar con algún médico de la casa, siempre sobre aspectos profesionales.

Lo acompañaba por los viejos pasillos, siempre dando la vuelta por el camino más largo, ya que evitaba cruzar por los pasillos centrales de la Facul-
Antoni Gelabert Mas Servicio y Catédra de Urología Hospital del Mar Passeig Maritim, 25 - 29 08003 Barcelona. (España). 36114@imas.imim.es 
tad; decía gustaba de ver los familiares y enfermos juntos paseando y departiendo sentados en los bancos o en sillas de ruedas, contemplar sus alegrías y sufrimientos, ya que esto, decía es la realidad de la medicina hospitalaria.

Cuando esto sucedía llevaba ya varios años jubilado y los médicos jóvenes no lo reconocían físicamente, se había vuelto menudo y un poquitín encorvado, la biología manda, si bien su nombre era reverenciado al oírlo, como tantas veces tuve ocasión de presenciar.

Recuerdo los momentos en que el Prof. P. Carretero, entonces joven Jefe de Servicio, recién llegado de su formación alemana, le traducía algunos artículos originales del alemán, para profundizar sobre los contenidos. Don Salvador se enfadaba mucho, mostraba estar muy enojado cuando se vertían conceptos que él no aprobaba o que estaba convencido de lo contrario.

También los largos monólogos cuando tenía que exponer alguna conferencia en algún foro internacional y lógicamente debía ser ya en inglés, idioma que él no dominaba, se lo aprendía de memoria y se lo recitaba una y otra vez al Dr. Carretero, quien con tanta paciencia y veneración aguantaba estoicamente "los largos minutos" de oyente.

Por lo tanto, como decía anteriormente, tuve el privilegio de conocerlo personalmente, pero no he trabajado con él, la diferencia de edad era abismal, por lo que mis recuerdos son vivencias humanas y anécdotas, no experiencias profesionales en un sentido científico.

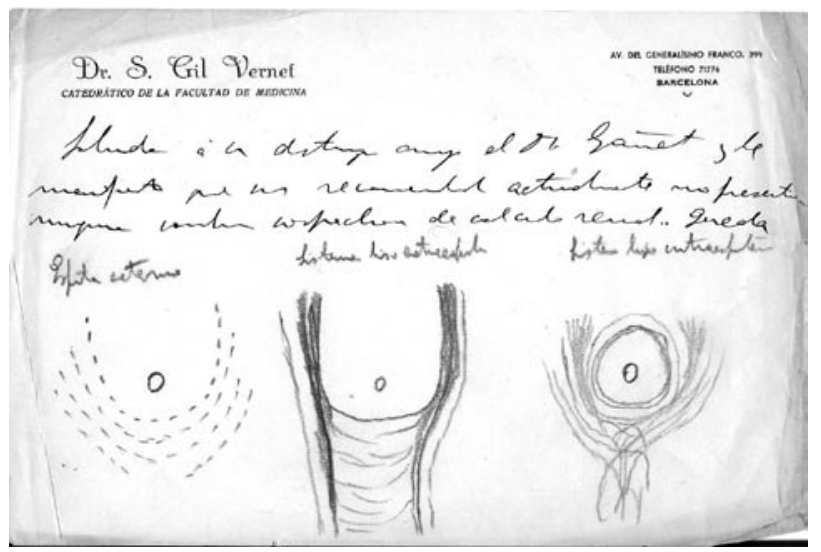

FIGURA 1. Papel / carta personal de Don Salvador con un inicio de saludo que es aprovechado para efectuar esbozos de la zona cérvico-uretral.

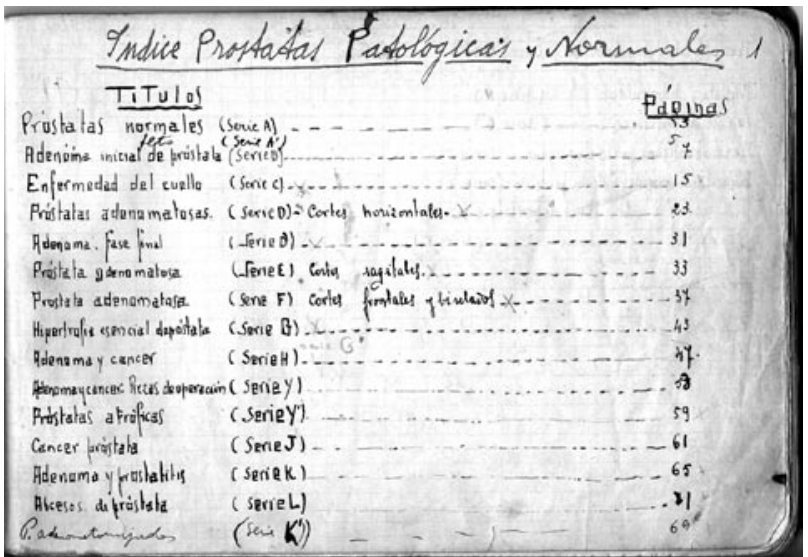

FIGURA 2. Índice de materias en que eran clasificados los hallazgos histopatológicos, base de sus investigaciones anatómicas. La pulcritud caligráfica ya indica la precisión metodológica de sus investigaciones.

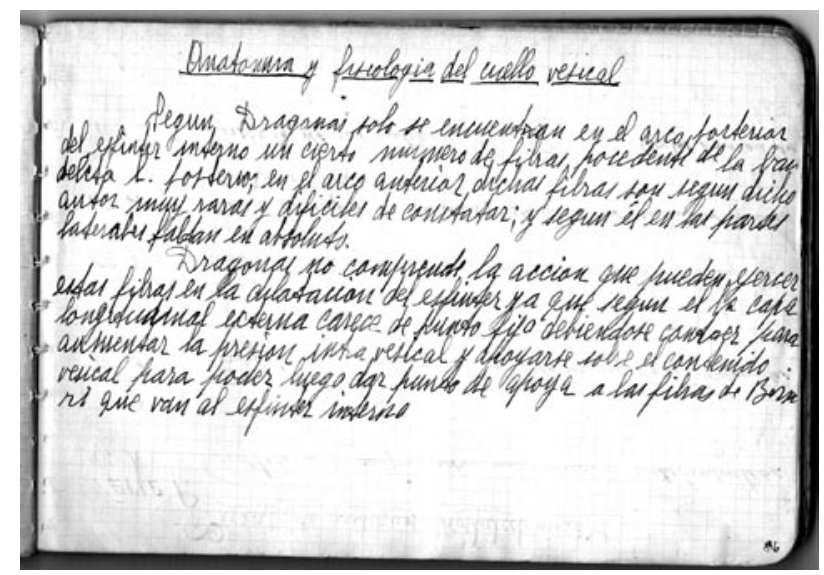

FIGURA 3. Texto de uno de los capítulos de su obra sobre la glándula prostática, en sus primeras fases de redactado.

Texto (sic): "Anatomía y fisiología del cuello vesical Según dragonas solo se encuentran en el arco posterior del esfínter interno un cierto número de fibras procedentes de la bandeleta I. posterior; en el arco anterior de dichas fibras son según dicho autor muy raras y dificules de constatar; y según él en las partes laterales faltan en absoluto.

Dragonas no comprende la acción que puedan ejercer estas fibraqs en la dilatación del esfirnter, ya que según é la capa longitudinal externa carece de punto fijo debiendose contraer para aumentar la presión intravesical y apuyarse sobre el contenido vesical para poder luego dar punto de apoyo a las fibras de....... que van al esfínter interno." 


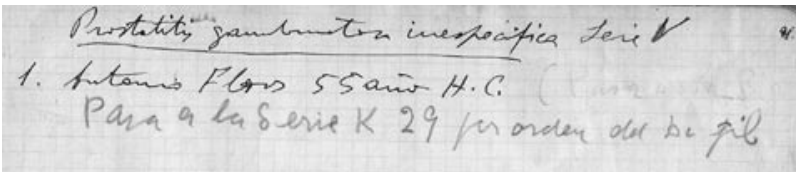

FIGURA 4. Detalle de referencia de un caso que ofrecia interés especial al que "por orden del Dr. Gil" se selecciona.

Sin embargo no puedo resistirme a ofrecer a la Historia de la Urología española, en mayúsculas, una vivencia que presencié: la discusión acalorada frente a un microscopio monocular, entre el Prof. Salvador Gil Vernet y el Prof. Hutch a raíz de una visita de éste último a Barcelona, allá por los años 1975-76.

La polémica giró, no podía ser otra, en torno a las fibras de decusación del uréter terminal, las que constituyen el trígono superficial, según Gil Vernet, y se insertan en el cuello-uretra prostático.

Había varias preparaciones histológicas e histo-topográficas (de gran formato como él utilizaba entonces) y que se iban colocando sucesivamente bajo el objetivo del microscopio; alternativamente ellos dos iban observando los detalles histológicos y señalando lo que para uno era una evidencia irrefutable para el otro carecía de la especificidad y función que se le imputaba a dichas estructuras; la discusión iba subiendo de tono, hablando uno en inglés y el otro en castellano, con algún vocablo duro en catalán, mientras iban traduciendo el diálogo el Dr. P. Carretero, el Dr. C. Guerra, adjunto del Servicio, y un ayudante del Prof. Hutch.

Fue una auténtica sesión memorable el poder asistir al privilegio del enfrentamiento intelectual y científico entre dos gigantes de la ciencia urológica
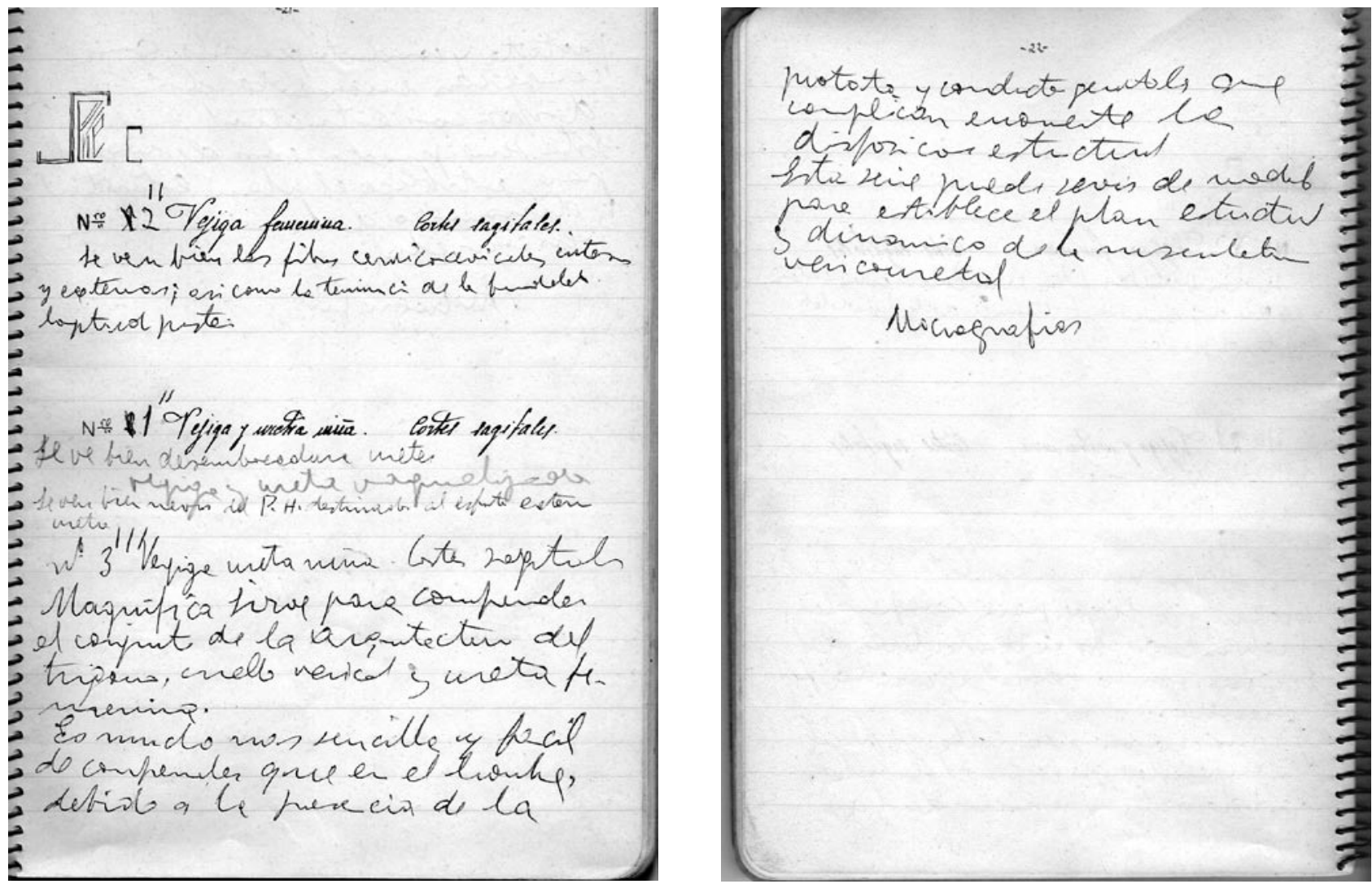

FIGURA 5. a-b.- Comentarios a unos cortes sagitales. La referida a la Vejiga y Uretra de niña. Cortes sagitales. Pags 21 y 22 (sic): "Vejiga de niña Cortes sagitales"

Magnífica sirve para comprender el conjunto de la arquitectura del trígono, cuello vesical y uretra femenina. Es mucho más sencilla y fácil de comprender que en el hombre debido a la presencia de la próstata y conductos genitales que complican enormemente la disposición estructural. Esta serie puede servir de modelo para establecer el plan estructural dinámico de la musculatura vesicouretral... 


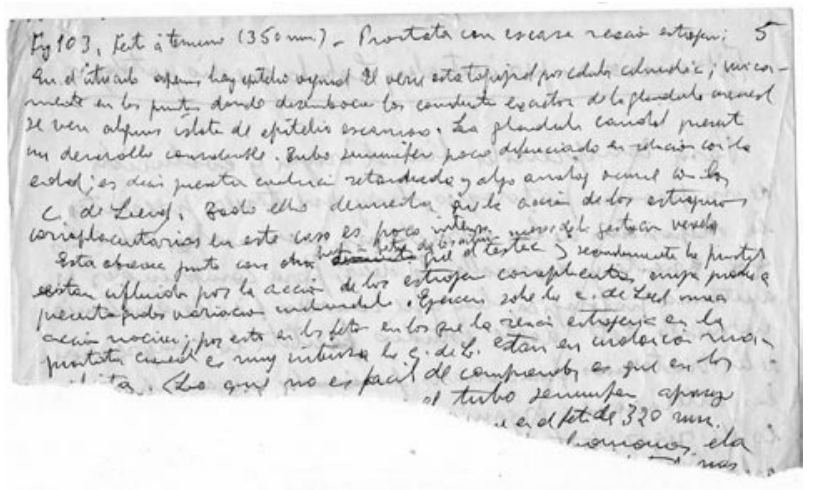

FIGURA 6.Descripción de un aspecto fundamental de sus investigaciones: las interacciones entre próstata, testes y hormonas corioplacentarias durante el período fetal.

Trascripción (sic): "Fig 103. Feto a término /350 $\mathrm{mmm})$. Próstata con escasa reacción estrogénica: en el utrículo apenas hay epitelio veginal. El veru está tapizado por células cilíndricas; únicamente en los puntos donde desembocan los conductos excretores de la glándula craneal se ven algunos islotes de epitelio escamoso. La glándula caudal presenta un desarrollo considerable. Tubo seminífero poco diferenciado en relación con la edad; es decir presenta maduración retardada y algo análogo ocurre con las C. de Leydig. Todo demuestra que la acción de los estrógenos corioplacentarios en este caso es poco intenso. Está observación junto con otros......fetos de los mismos meses de la gestación...... están influidos por la acción de los estrógenos corioplacentarios cuya producción presenta grandes variaciones ..... Ejercen sobre las $C$. de Leydig una acción nociva; por esto en los fetos en los que la reacción estrogénica en la próstata caudal es muy intensa las C. de Leydig están en coloración más ...... Lo que no es fácil de comprender es que en los .......el tubo seminifero aparezca..... feto de $320 \mathrm{~mm} . . . "$

universal, ambos ya desaparecidos, que defendían concepciones anatomo-funcionales radicalmente distintas.

Pero el hecho de haber trabajado profesionalmente en aquella casa durante 12 años, unos como alumno-estudiante interno, una figura histórica de los tres últimos años de la licenciatura, posteriormente los años de formación MIR y luego varios más como médico adjunto, me permitieron tener contactos frecuentes con su figura y al mismo tiempo asistir a los cambios estructurales del servicio y también a los cambios arquitectónicos del mismo para adaptarlos a las nuevas necesidades asistenciales.

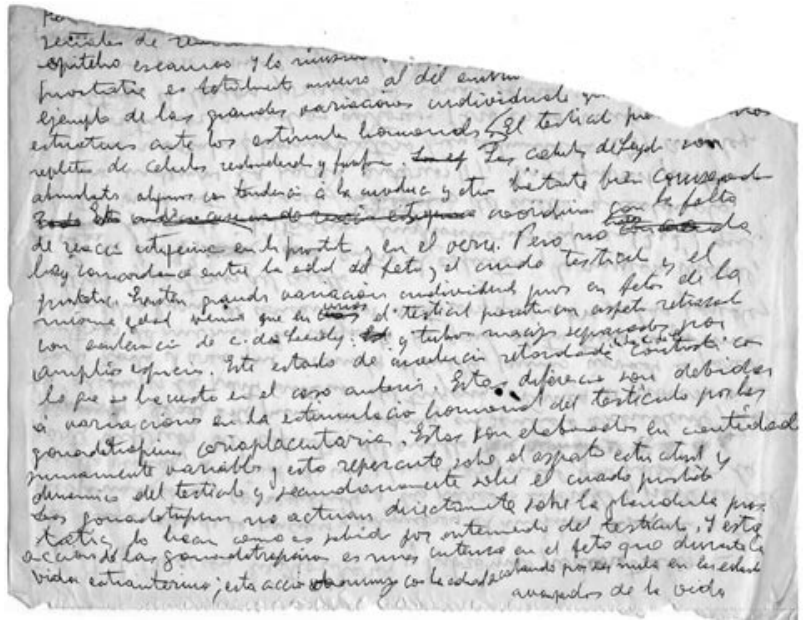

FIGURA 7. Posiblemente se trata del mismo estudio que la imagen anterior, ya que se trata de la misma temática, el papel es idéntico y la letra parece ofrecer continuidad.

\section{Trascripción (sic):}

"señales de .......epitelio escamoso y lo mismo...prostática es totalmente .... del... ejemplo de las grandes variaciones individuales....estructuras ante los estímulos hormonales. $\sqrt{ }$ El testículo repleto de células redondeadas y fusiformes. Las células de Leydig son abundantes algunas con tendencia a la maduración y otras bastate bien conservadas. Esto coordina con la falta de reacción estrogénicas en la próstata y en el veru. Pero no hay concordancia entre la edad del feto y el cuadro testicular y el prostático. Existen grandes variaciones individuales pero en fetos de la misma edad vemos que en unos el testiculo presenta un aspecto retrasado con abundancia de C. de Leydig y tubulos macizos separados por amplios espacios. Este estado de maduración retardada de las C. de Leydig contrasta con lo que se demuestra en el caso anterior. Estas diferencias son debidas a variaciones en la estimulación hormonal del testiculo por las gonadotropinas coriónicas.

Estas son elaboradas en cantidades pemanentemente variables y esto repercute sobre el aspecto estructual y dinámico del testiculo y secundariamente sobre el cuadro prostático. Las gonadotropinas no actuan directamente sobre la glándula prostática, lo hacen como es sabido por intermedio del testículo. Y esta acción de las gonadotropinas es mas intenso en el feto que durante la vida intrauterina; esta acción disminuye con la edad acabando por ser nula en las edades avanzadas de la vida.

Bien, pues en relación a este aspecto último es donde radica el motivo de mi participación en esta obra de recuerdo histórico. Podríamos remontarnos a muchos siglos para constatar que la historia 
SOCIEDAD INTERNACIONAL DE UROLOGIA

MERDENTE:
MOOT, SALVADOR GIL VERNET

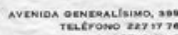

FIGURA 8. Cabecera del papel/carta de la SIU cuando Don Salvador era el presidente.

de nuestros países ha tenido alocados episodios de hogueras en las que, con irracional intención de purificar el espíritu del pueblo, se echaba a las mismas obras capitales del pensamiento racional del hombre, despreciando el conocimiento; pues un episodio parecido, si bien no fruto de la irracional ira, sino de la miserable ignorancia, me permitió disponer actualmente de algunos "cuadernos de campo" de las investigaciones anatómicas del equipo de Don Salvador, en los que de manera metodológica se iban recogiendo los detalles de las piezas de anatomía que iban examinando, así como algunos bocetos de dibujos histológicos fruto de la observación microscópica.

La anécdota sucedió de manera esperpéntica. Estaba yo de guardia de presencia física los días en que se efectuaban las obras de remodelación del Servicio de Urología y los escombros de las obras se echaban en un contenedor metálico colocado al efecto al exterior; por una ventana cuyos cristales se habían roto adrede se arrojaba todo el material de las obras, contenido de la vitrinas, libros, cuadernos, matraces, pipetas, mecheros de cristal, entre otros muchos utensilios de laboratorio, los cajones de las vitrinas y su contenido, de manera especialmente abundante laminillas de preparaciones histológicas e histo-topográficas, es decir, todo el material que se hallaba en la habitación del ángulo sur, planta baja del Clínic. De manera casual, ojeaba como se iba acumulando el material de deshecho, observé que entre aquellos escombros había material gráfico, dibujos hechos a mano, preparaciones "laminillas" histológicas, algunas, pocas, enteras, la inmensa mayoría rotas, y cuadernos ya viejos, dibujos de gran formato hechos a mano que reproducían histologías observadas a través del microscopio, ya que al no haber entonces cámaras fotográficas adaptadas para captar la imagen del microscopio, se dibujaba lo observado. Durante el descanso de la noche y amparado en la penumbra, me acerqué al contenedor y retiré lo que pude y que se hallaba en "buenas" condiciones; este material es el que voy a describir y comentar a lo largo de las siguientes páginas.

El material consta de 11 libretas de campo, con sus anotaciones y descripciones de las preparaciones anatómicas macro y microscópicas. Existe además un cuaderno con varios dibujos hechos a mano y a lápiz de mina negra, que reproducen la anatomía microscópica del cuello; además cinco láminas de formato $60 \times 40 \mathrm{~cm}$. de dibujos histológicos, varias preparaciones histológicas, así como algunos papeles de carta con el membrete de Don Salvador en sus distintas facetas institucionales. 